\title{
Impact Of Retirement System On Job Satisfaction And Loyalty: A Case Of The Salary Peak System
}

Yeji Kim, Graduate, KDI School of Public Policy and Management, South Korea Yoon C. Cho, Professor, KDI School of Public Policy and Management, South Korea

\begin{abstract}
The salary peak system, developed as a replacement for the early retirement system, provides properties such as extension of the retirement age, decreased salary, and/or changes of job position. The purpose of this study is to explore the perceived attitudes toward the salary peak system, as well as job performance, satisfaction, and loyalty. In particular, this study investigates i) the effects of monetary variables (e.g., salary, incentive, pension); ii) the effects of the non-monetary variables (e.g., word of mouth, position, perceived job importance, organizational commitment); iii) the effects of overall attitudes on job performance; iv) the effects of job performance on satisfaction; and v) effects of satisfaction on loyalty. This study applied various theories and models to explain job performance, satisfaction, and loyalty. In order to measure the findings, this paper conducted surveys and applied statistical analysis using factor analysis and regression. The result provided consideration on old worker's job motivation, satisfaction, and loyalty or intention to leave regarding how to apply the system. This study provides implications for management and public policy for a retirement system. This study suggests the need for the development of effective management and public policies for the salary and retirement system without decreasing motivation, satisfaction, and loyalty.
\end{abstract}

Keywords: Salary Peak System; Retirement; Re-Employment; Salary; Pension; Motivation; Job Satisfaction; Loyalty

\section{INTRODUCTION}

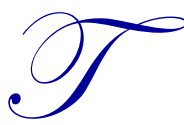

he aging of society is a widespread phenomenon occurring in many countries. Governments and companies have been trying to develop policies and plans for an aging society with consideration of diverse perspectives including demographic, economic, sociological, and political. As retirement has become a major consideration in an aging society, most of the public sector as well as private companies have developed a seniority-based system by considering worker's tenure rather than work performance (Hwang 2006). Under the seniority-based system, the retirement age was guaranteed until a predetermined certain age, called the age of retirement (Lee, 2009). Retirement systems are also determined based on years of labor or on age in position (Lee, 2009). Under the current retirement system, companies assume the burden of managing older workers with the high salary under the pay step or salary class system (Yoo and Ha, 2010). For such reasons, private companies have made an effort to change the system by combining the pay step system with a performance-related system, which determines salary based on job performance.

A newly adopted system called the salary peak system, as a type of wage peak system, cuts wages when a worker reaches a certain age, balancing this by extending the worker's retirement age (http://www.mosf.go.kr). Many researchers (e.g., Byun and Kim, 2005; Han, 2013) have studied the salary peak system itself to determine its effectiveness. This article focused on the salary peak system by exploring its psychological influence on older workers experiencing the salary peak system. This study reviewed workers' psychological perceptions with respect to monetary and non-monetary changes under the salary peak system. In particular, this study investigates factors that affect attitudes toward salary peak system including i) monetary factors (salary, incentive and pension) and ii) non-monetary factors (word of mouth, position or employment status, perceived job importance and organizational 
commitment). Further, the purpose of the current study is to explore how the newly adopted salary peak system affects workers' motivation, satisfaction and loyalty. Well known theories such as Maslow's theory (Maslow, 1954), theory of reasoned action (Ajzen \& Fishbein, 1980), self-perception theory (Bem, 1967), expectancy theory (Vroom 1964), goal setting theory (Locke and Latham, 1990), motivation-hygiene theory (Herzberg, 1966), equity theory (Adam, 1963) and job characteristics theory (Richard and Seog, 2000) all support this study. Research questions for this study include the following:

i. How monetary factors such as wage, incentives and pension under the salary peak system affect older workers' attitudes

ii. How non-monetary factors such as word of mouth, position, perceived job importance and organizational commitment affect workers' attitudes towards the salary peak system

iii. How changed attitudes affect motivation in work performance

iv. How changed motivations in work performance after applying the salary peak system affect workers' satisfaction

v. How a change in job satisfaction after applying the salary peak system affects workers' loyalty to job/company

vi. How a change in satisfaction after applying the salary peak system affect older workers' intention to leave the job or company

\section{LITERATURE REVIEW}

Previous studies (e.g., Wachter, 2002; Eichhorst et al., 2011) have examined retirement and pension systems. Previous studies (e.g., Geneviève and Delsen, 1996; https://www.tiaacref.org) have introduced several types of retirement programs such as gradual retirement, phased retirement and early retirement. Ebbinghaus (2000) mentioned that highly available preretirement programs provide incentives for workers to retire and even exit early from work. Early retirement programs are preventive solutions to reduce many problems and psychological depression after retirement (Becker et al., 1983).

Most of retirement system pushes mandatory retirement enabling employers to force employees to retire at a certain age (Wachter, 2002). Barker and Clark (1980) insisted that mandatory retirement be a necessary policy for firms to get rid of older workers, even if they wish to work longer. Lazear (1979) also explained that mandatory retirement is a necessary employer action to deal with reduced productivity of older workers, promoting opportunities for younger workers instead. Wachter (2002) insisted on the abolishment of mandatory retirement in favor of the alternative of flexible retirement. Pensions (http://www.oecd.org) become an alternative income for retirees, even though consideration of the affordability and financial stability of pensions. A study by Eichhorst et al. (2011) stated extension of the retirement age and early retirement abolishment by reforming the pension system for an aging society. While there are various problems raised by all types of the retirement system, this study investigates the effectiveness of a salary peak system as a special case. Gradual retirement system has been introduced in several European countries to let older workers more participate in labor market (Elsayed, Grip, Fouarge, \& Montizaan, 2014).

\section{Salary Peak System: A Special Case of Retirement System}

The purpose of the salary peak system is to maintain employment of the old in rapid aging societies and create a flexible labor market in the global era (Han, 2013). Under the salary peak system, employees could extend their retirement age or to be re-employed while taking a reduced salary (http://www.moel.go.kr). A work-sharing program as a similar system is utilized to avoid layoffs and instead lets employees rotate with reduced working hours and wages (http://www.edd.ca.gov/). The salary peak system, in contrast to a work sharing program, reduces salary when the level of wage reaches a certain peak (Lee \& Kim, 2006). The salary peak system lightens cost load and guarantees job security (Lee and Kim, 2006). This system is a win-win strategy for both companies and employees (Byun and Kim, 2005). Table 1 summarizes a comparison analysis of the retirement system and the salary peak system. The salary peak system is introduced as the compromise to solve both labor cost burdens for companies and workers' concerns about job stability and early retirement age (Lee et al., 2012). Other retirement systems such as the gradual retirement program based in the U.S., allows workers to leave gradually and remain 
later (Geneviève and Delsen, 1996), also called phased retirement program (http://assets.aarp.org/). A charity called Age UK supports older people by introducing some guides (http://www.ageuk.org.uk).

\section{Effectiveness of Salary Peak System}

The Economic and Social Development Commission suggests that an effective salary peak system will contribute to resolving the problem of youth unemployment in Korea (http://www.esdc.go.kr). According to Tae et al. (2009), active utilization of salary peak system will reduce the labor cost burden to companies. Based on real cases, such as that of the salary peak system of the Korea Credit Guarantee Fund, older workers are able to maintain their social status through working activities and expected rise in wages compared to early retirement (Lee, 2006). Kim (2012) stated that a salary peak system enables older workers to work positively despite decreasing wages or demotion to a lower position. Kim (2012) also addressed that it contributes to improvement in the company's image and enhancing worker loyalty. However, various studies do suggest some drawbacks to the system. Kim (2014) stated that workers are opposing salary peak system because the extension of retirement age should not be accompanied by pay cuts. An (2003) argued that the salary peak system can be easily abused by companies in terms of reducing salaries instead of increasing employment. Based on Choi (2013), the salary peak system will cause conflicts between the financial sector and the labor sector due to each other's disagreement. Kim (2012) indicated that the salary peak system creates conflicts among generations or positions. Further, An (2011) researched that salary peak system is not effective solution for the social problem of unemployment. Therefore, there are both positive and negative expectations as to how a salary peak system might affect the labor management world.

\section{THEORETICAL BACKGROUND}

Various theories and models support the effects of the salary peak system on motivation, attitudes, performance, job satisfaction, and loyalty. Maslow's theory (Maslow, 1954), the most fundamental study concerning human needs can be applied to investigate older workers' reaction to the salary peak system and any behavior changes observed. The theory of reasoned action (Ajzen \& Fishbein, 1980) investigates that humans are logical individuals who can process information in order to come up with a reasonable behavioral decision. Self-perception theory (Bem, 1965, 1972) explains individual' attitudes, feelings, and beliefs in external circumstances (Scott, 1978). Expectancy theory (Vroom 1964; Van Eerde \& Thierry, 1996) as the representative theory of work motivation concerned with individual behavior as expectations shaped according to worker effort and performance. Affect theory (Hussain and Khalid, 2011) also argues that worker's expectation of work and what the worker is getting from the work affects workers' satisfaction level (Hussain and Khalid, 2011). This theory could be adopted to predict older workers' motivation, satisfaction and loyalty based on their attitudes or perceptions of the salary peak system. Further, the goal-setting theory suggested by Locke and Latham (1990) explains that high goal-setting will lead to high commitment and high performance. Herzberg's motivation (Herzberg, 1966) and hygiene theory discussed motivation and dissatisfaction studies (Hussain and Khalid, 2011). Equity theory (Adams, 1963) also explained that workers expect a fair return for their contribution to a job or company.

\section{HYPOTHESES DEVELOPMENT}

This study classified factors related to perception and attitudes on the salary peak system into monetary and nonmonetary factor. Monetary factors include salary, incentives, and pension, while non-monetary factors include word of mouth, job position or employment status, perceived job importance, and organizational commitment. This study also investigates i) the effects of monetary and non-monetary factors on attitudes towards the salary peak system; ii) the effects of attitudes on motivation on job performance; iii) the effects of motivation on job performance on satisfaction; and iv) the effects of job satisfaction on loyalty and intention to leave. Figure 1 summarizes the effects of perception of the salary peak system to behavior changes. 
Figure 1. Model of Attitudes, Motivation, Satisfaction and Loyalty toward Salary Peak System

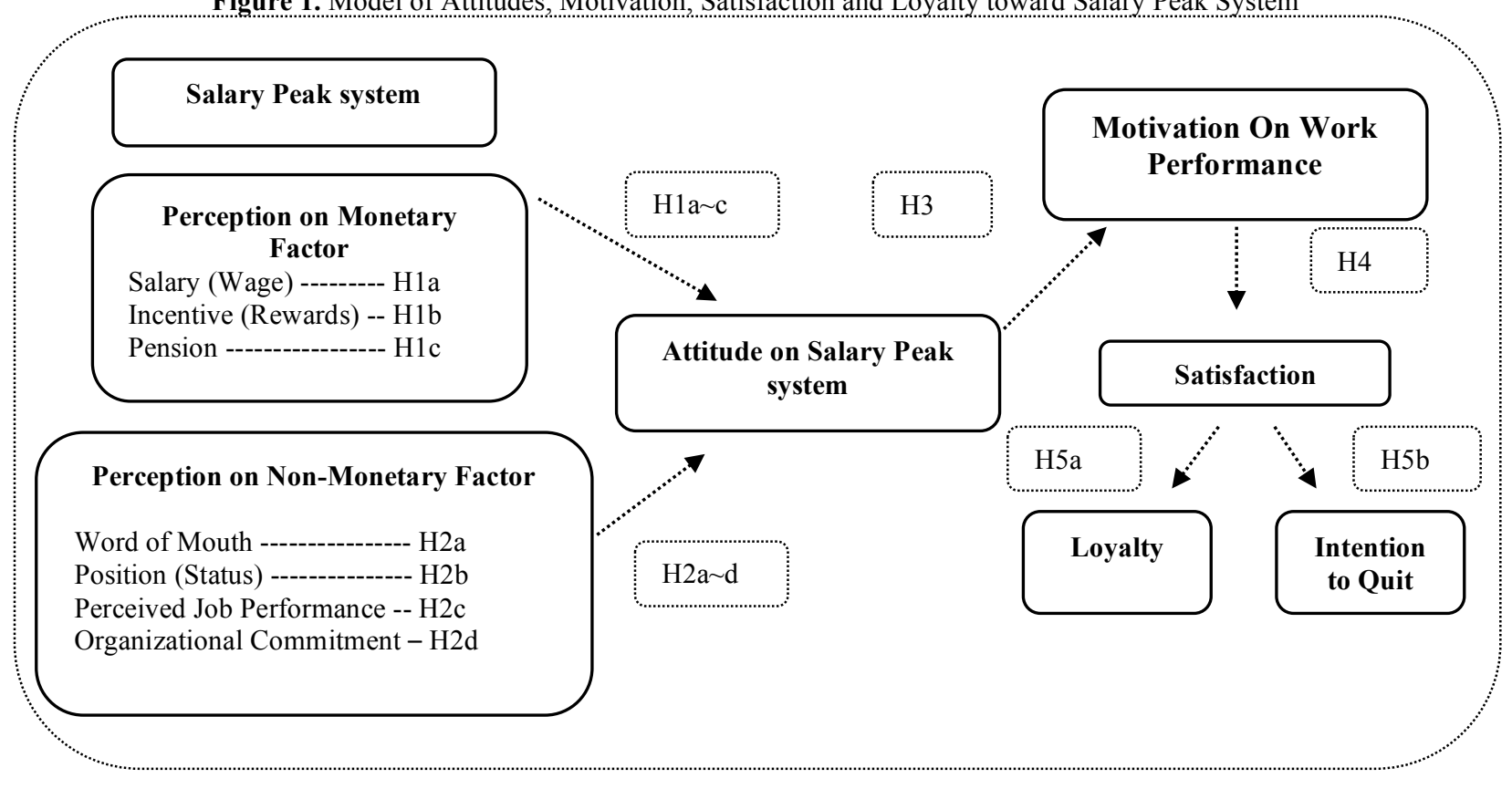

\section{Effects of Monetary Factors on Attitudes towards Salary Peak System}

Zedelius, Veling, Erik, and Henk, (2012) explained that monetary factors such as money is one of the most effective tools to lead actions and improves performance by making people prepare before they are actually in the process of completing rewarded tasks. If the salary peak system is applied, there might be changes in salary, incentives and pension among other monetary factors in return for an extended retirement age. So this study investigates the effect of those three monetary factors such as salary, incentives and pension on attitudes towards the salary peak system. This paper proposed monetary factors due to following: i) the impact of changed wage on attitudes towards salary peak system; ii) the impact of changed incentives on attitudes toward the salary peak system; and iii) the impact of changed pension due to extended retirement age on attitudes toward the salary peak system.

\section{Effects of Changed Salary on Attitudes towards the Salary Peak System}

Salary is paid in return for one's labor and is one of the most important factors determining job satisfaction (Clark and Oswald, 1996). Employees tend to pay attention to changes of salary because it can be a standard to predict how employers regard their employees relative to peers (Rynes, Gerhart and Minette, 2004). When peers can compare salary if the company discloses salary information for all workers, they easily fall into dissatisfaction or discontent (Card et al., 2012). This study firstly focuses on salary among monetary factors to investigate the effects of changed salaries on attitudes toward the salary peak system. This study hypothesized that changed salary affects attitude toward the salary peak system.

H1a: Perception on changed salary affects attitudes toward the salary peak system.

\section{Effects of Changed Incentives on Attitudes towards Salary Peak System}

In addition to salary, incentives are a monetary factor as well. Mehta (2014) also insisted that monetary incentives have the close relationship with job satisfaction, when, for example, employee feel rewarded if they receive rewards equally or more than other colleagues based on their performance. Monetary incentives are effective motivators that lead to higher motivation and better performance (Nandanwar, Surnis, and Nandanwar, 2010). This study hypothesized that changed incentives affect attitudes toward the salary peak system. 
H1b: Perception on changed incentives affects attitudes toward the salary peak system.

\section{Effects of Changed Pensions on Attitudes toward the Salary Peak System}

Retirement no longer means the end of working and many retirees want to work in later life (Merrill Lynch, 2014). The last important monetary factor is pensions, which is related to retirement. Naegele, Dhéret, and Thode (2013) explained that the pension system rewards people who work longer and enables them to start a second career. This study hypothesized that a changed pension system would affect attitudes towards the salary peak system.

H1c: Perception on changed pension system affects attitudes toward the salary peak system.

\section{Effects of Non-Monetary Factors on Attitudes towards Salary Peak System}

Although monetary factors play an important role in affecting attitudes, non-monetary factors should be also considered. Motivation-Hygiene theory (Herzberg, 1966) already proposed that non-monetary factors could be as effective tools with respect to motivation as much as monetary factors (Charity and Timinepere, 2011). Nonmonetary factors are also effective in attracting, rewarding, motivating and retaining workers (Abdullah, 2013). Bari, Arif, and Shoaib (2013) also state that non-financial rewards can change a worker's behavior positively and bring better performance This study examines attitudinal changes by focusing on non-monetary factors including word of mouth, job position, job importance and organizational commitment. This study proposed non-monetary factors including the following: i) the impact of opinion via word of mouth on attitudes about the salary peak system; ii) the impact of changed position or employment status on attitudes toward the salary peak system; iii) the impact of perceived job importance on attitudes toward the salary peak system; and iv) the impact of organizational commitment on attitudes toward the salary peak system.

\section{Effects of Word of Mouth on Attitudes toward the Salary Peak System}

Perception of other's behavior can induce mimicry or imitation in one's next action unintentionally, which leads to a cycle of social interaction known as the Chameleon effect (Chartrand and Bargh, 1999). A customer's experiences and perceptions of goods and services are spread through word of mouth whether positive or negative (Buttle, 1998). According to this concept of behavior study, word of mouth influences other's attitudes and behaviors, so it is important for social relationships (Markus and Kitayama, 1991 cited in Buttle, 1998). Based on this consideration, this study hypothesizes the effects of word of mouth on attitudes toward the salary peak system.

H2a: Perceptions from word of mouth affect attitudes on the salary peak system.

\section{Effects of Position or Employment Status on Attitudes toward the Salary Peak System}

Job position could be a motivator based on Vroom's expectancy theory (Vroom 1964) and good performance results in promotion (Waskiewicz, 1999). Demotion could be a penalty due to underperformance (Van Dalen and Henkens, 2014). Job position means not only a workers' physical place in the among hierarchical structure but also the workers' performance-related place. Employment status is also an important factor that affects worker's motivation and satisfaction. Employment status is related to job security, which is the concept of the worker's expectation of job continuity at work (Davy, Kinicki, \& Scheck, 1997). If employment status is changed or job security becomes weaker, workers might feel job insecurity. Job insecurity could cause worker dissatisfaction, weakened organizational commitment or decreased dedication to the company because it breaks a psychological contract between employer and employee based on psychological contract theory (Rousseau, 1995). This study hypothesizes effects of position or employment status on attitudes toward the salary peak system.

H2b: Change of position affects attitudes on salary peak system.

Effects of Perceived Job Importance on Attitudes towards Salary Peak System 
Job importance refers to how important a worker considers their job to be for them. The higher the degree of autonomy, is allowed on the job, the more workers consider their abilities and skills as important (Parker, 1998). Furthermore, job enrichment would be increased if workers can participate in decision-making and control over the job (Parker, 1998). Based on strong job autonomy and job enrichment, workers seem to think that their job is an important part of the organization. This study hypothesizes that perceived job performance affects attitudes toward the salary peak system.

H2c: Perceived job importance affects attitudes toward the salary peak.

\section{Effects of Organizational Commitment on Attitudes toward the Salary Peak System}

In addition to one's perceived job importance, there is another non-monetary factor in the study, which is organizational commitment. Organizational commitment refers to the workers' degree of involvement in the organization (Suma and Lesha, 2013). Higher organizational commitment enables workers to make extra efforts in meeting organizational goals (Neyshabor and Rashidi, 2013). Yasar, Emhan and Ebere (2014) stated that organizational commitment is a crucial factor in organizational profitability since high commitment brings good performance. Thus, this study hypothesizes effects of organizational commitment on attitudes toward the salary peak system.

H2d: People have different attitudes toward the salary peak system based on their organizational commitment.

\section{Effects of Attitudes towards Salary Peak System on Motivation for Job Performance}

Expectancy theory (Van Eerde and Thierry, 1996) and goal-setting theory (Locke, and Latham, 1990) address the idea that high expectation and high goals will lead workers to be more motivated toward high job performance. Utman (1997) stated that the high pressure of motivation to goals facilitates high performance. The manager's primary duty is to motivate workers to achieve organizational goals effectively and efficiently (Azar and Shafighi, 2013). This study hypothesizes that attitudes toward the salary peak system negatively affect motivation for work performance.

H3: Decreased attitudes toward the salary peak system have the negative impact on motivation for work performance.

\section{Effects of Job Performance on Satisfaction}

Utman (1997) also argued that highly motivated involved and self-determined worker tend toward better performance and higher satisfaction. Job satisfaction refers to workers' attitudes towards their job (Pandey and Khare, 2012). Job satisfaction is also the degree of how much workers like the job and how motivated they are to help the company approach goals (Karimi, Malik and Hussain, 2011). Performance and satisfaction became important keys for the success of organizations and were considered to be assessment tools for worker behavior and performance under the name of human resource management (Sudin, 2011). This study hypothesizes that decreased motivation for job performance negatively affects satisfaction.

H4: Decreased motivation for work performance affects employees' dissatisfaction.

\section{Effects of Satisfaction on Loyalty}

Even though it is arguable whether satisfaction and organizational commitment are equally important, past studies found that job satisfaction is a crucial predictor of organizational commitment (Pandey and Khare, 2012). Based on expectancy theory (Van Eerde and Thierry, 1996), workers expect their achievement to be rewarded with bonuses, promotion or recognition. The positive relationship between satisfaction and organizational commitment falls under the broader category of loyalty (Pandey and Khare, 2012). Workers who are highly satisfied and devote themselves to the job might have high loyalty and vice versa. Furthermore, high loyalty guarantees high retention of employees 
for organizations, but low loyalty leads to a high intention to leave. This study hypothesized that the negative side of satisfaction negatively affects loyalty.

H5a: Job dissatisfaction causes the decrease of loyalty.

\section{Effects of Satisfaction on Intention to Leave}

In contrast to the higher loyalty of employees, employees sometimes intend to leave. Intention to leave the job could have several meanings; for example, better career development in a positive way, retirement in a neutral way, or self-decision due to dissatisfaction in a negative way (Arshad, Masood and Amin, 2013). In a study conducted by Basak et al., (2013), it is found that satisfaction directly affects intention to leave, so highly satisfied employees would be less likely to intend to leave their work. The dissatisfaction of workers will trigger a desire to quit their jobs, which then increases turnover (Choi et al., 2012). In addition, employees who have low loyalty are also expected to leave (Wan, 2012). This study hypothesized that the negative side of satisfaction affects the intention to leave.

H5b: Job dissatisfaction leads to employees' intention to leave.

\section{METHODOLOGY}

This study conducted an online survey to measure employees' attitudes and opinions on the salary peak system. This study examines the effects of monetary factors such as salary, incentive and pension on attitudes toward the salary peak system. Secondly, this study also investigates effects of non-monetary factors such as word of mouth, job position, perceived job importance and organizational commitment. Further, this study investigates relationships between motivation and work performance, satisfaction, loyalty and intention to leave.

The study was distributed to 166 people, and a total of 132 respondents completed the survey, with a response rate of $81 \%$. All respondents were randomly chosen in Korea. Respondents who are familiar with salary peak system were selected in this study. From the scale on familiarity of the salary peak system, respondents who select familiar and very familiar were selected. The questionnaire was developed in English and translated to Korean. Backtranslation technique was applied. The questionnaire in the survey mainly consists of two major parts to ask opinions based on attitudes toward the salary peak system according to monetary factors, non-monetary factors, and psychological factors such as motivation, satisfaction and loyalty. This study applied a five-point Likert scale with higher numbers indicating higher levels (5) of negative feelings such as strongly disagree or least dissatisfied and with smaller numbers (1) representing higher levels of positive feelings such as strongly agree or highly likely. The items in the survey are developed from previous studies (Zedelius et al., 2012; Charity \& Timinepere, 2011; Utman, 1997; Pandey \& Khare, 2012; Basak, Ekmekci, Bayram, \& Bas, 2013) and also behavior-related theories (Ajzen \& Fishbein, 1980; Bem, 1967; Vroom 1964), These items are modified to support the aim of this study.

\section{DATA ANALYSIS}

\section{Respondents Demographics}

Of 132 respondents, $70.5 \%$ are male and $28 \%$ are female. $61 \%$ were married and $39 \%$ were single. Around $18.9 \%$ are between the ages of $20-29$ years old; $39.4 \%$ are between the ages of $30-39$ years old; approximately $31.8 \%$ are between the ages of $40-49$ years old; $6.8 \%$ are between the ages of 50-55; lastly $56-60$ or over 60 years old are around $1.5 \%$. In addition, more than $90 \%$ have a graduate degree $(40.9 \%)$ and a master's degree $(50 \%)$. In terms of annual income, about $16.7 \%$ earn less than $\$ 40,000 ; 36.4 \%$ earn between $\$ 40,000$ and $\$ 60,000 ; 17.4 \%$ earn between $\$ 60,000$ and $\$ 80,000$ and lastly only $13.6 \%$ earn more than $\$ 100,000$. Respondents are employees who are before retirement or whose jobs are subject to the salary peak system. $44 \%$ are at the position of assistant manager and manager, $15.9 \%$ are general managers, and the rest has the position of director or public officer. Almost $30 \%$ are working in the financial sector or for public organizations. $12.9 \%$ have $1-3$ years of working the same job, $21.2 \%$ have $3-5$ years, $20.5 \%$ have $5-10$ years of seniority, $28 \%$ have $10-20$ years of seniority, and $15.2 \%$ have more than 
20 years of working history in the same job. Lastly, in the case of responses based on whether or not their companies have a labor union, there is an almost fairly equal distribution, as $53 \%$ versus $46 \%$.

\section{Hypotheses Testing}

This study applied Cronbach's alpha to check the reliability of multi-item scales. This study found that Cronbach's alpha for monetary factors and non-monetary factors are above 0.80 . This study also found that Cronbach's alpha as follows: 0.89 for the effects of salary on attitudes toward the salary peak system, 0.85 for the effects of incentives, 0.83 for job position or employment status, 0.60 for job importance, 0.76 for organizational commitment, and 0.85 for overall attitudes towards salary peak system. This study also applied factor analysis to examine the validity of constructs. Using principal components analyses as the extraction method and Varimax rotation methods with Kaiser Normalization, the most relevant data emerged. This study considers main variables with Eigen values over 1.00. Table 1 shows factor analysis for overall attitudes toward salary peak system.

Table 1. Factor Analysis for Overall Attitudes toward Salary peak system Overall Attitudes towards Salary Peak System Component 1

\begin{tabular}{lc}
\hline How much do you overall evaluate salary peak system? & .90 \\
How much do you believe salary peak system itself? & .84 \\
How much do you think that salary peak system is important for the retirement plan? & .83 \\
How much do you like to work with workers who choose salary peak instead of retirement? & .74 \\
\hline
\end{tabular}

This study applied regression analyses using factor scores for the effects of each monetary or non-monetary factor on attitudes toward the salary peak system. The results of the ANOVA for the effects of monetary factors on attitudes toward the salary peak system found the models significant at the 0.01 level with $p=.00, F=114.08(r$ square $=.48)$. The results of the ANOVA for the effects of non-monetary factors on attitudes toward the salary peak system found that the model is significant at the 0.01 level with $p=.00, F=85.76(r$-square $=.40)$. As shown in Table 2 and 3, hypotheses for monetary factors (H1a $\sim \mathrm{H} 1 \mathrm{c}$ : Table 2) and non-monetary factors (H2a $\sim \mathrm{H} 2 \mathrm{~d}$ : Table 3 ) found significant. ANOVA result for the effects of attitudes toward the salary peak system on motivation on job performance found that the model is significant at the 0.01 level with $p=.00, F=113.80$ ( $r$-square $=.47)$. ANOVA result for the effects of motivation on job performance on job dissatisfaction also indicated that this model is significant at the 0.01 level with $p=.00, F=283.37$ ( $r$-square $=.69$ ). As shown in Table 4 , the effects of attitude towards salary peak system on motivation on job performance (H3) and the effects of motivation on job performance on job dissatisfaction (H4) found significant. Therefore, $\mathrm{H} 3$ and $\mathrm{H} 4$ are accepted. ANOVA result for the effects of job dissatisfaction on loyalty found that the model is significant at the 0.01 level with $p=.00, F=$ 213.37 ( $r$-square $=.63$ ). As shown in Table 4, the effects of job dissatisfaction on loyalty (H5a) found significant. Therefore, H5a are supported. Lastly, ANOVA result for the effects of job dissatisfaction on intention to leave found that the model is significant at the 0.01 level with $p=.00, F=48.21$ ( $r$-square $=.27)$. As shown in Table 5 , the effects of job dissatisfaction on loyalty (H5a) found significant. This study also accepted H5b.

Table 2. Summary of the Effects of Monetary factors towards Salary peak system

\begin{tabular}{lc}
\hline \multicolumn{1}{c}{ Variable (Independent -> Dependent) } & Standardized Coefficient \\
\hline Salary $->$ Attitudes toward Salary peak system $(\mathrm{H} 1 \mathrm{a})$ & $0.69(10.68 * * *)$ \\
Incentive-> Attitudes toward Salary peak system (H1b) & $0.61(8.63 * * *)$ \\
Pension -> Attitudes toward Salary peak system (H1c) & $0.71\left(11.48^{* * *}\right)$ \\
\hline$* * *$ Significant at 0.01 (2-tailed test)
\end{tabular}

Table 3. Summary of the Effects of Non-Monetary factors towards Salary peak system

\begin{tabular}{lc}
\hline \multicolumn{1}{c}{ Variable (Independent -> Dependent) } & Standardized Coefficient \\
\hline Word of Mouth -> Attitudes toward Salary peak system (H2a) & $0.41(5.02 * * *)$ \\
Position or Employment status-> Attitudes toward Salary peak system (H2b) & $0.62(8.79 * * *)$ \\
Perceived Job Importance -> Attitudes toward Salary peak system (H2c) & $0.61(8.71 * * *)$ \\
Organizational Commitment -> Attitudes toward Salary peak system (H2d) & $0.63(9.26 * * *)$ \\
\hline$* * *$ Significant at 0.01 (2-tailed test)
\end{tabular}


Table 4. Summary of the Effects of Attitudes toward Salary

peak system on Job Motivation, Satisfaction, Loyalty and Intention to leave

Variable (Independent -> Dependent)

Standardized Coefficient

Attitudes towards Salary peak system -> Motivation on Job performance (H3)

Motivation on Job performance-> Job Satisfaction (H4)

Job Dissatisfaction -> Loyalty (H5a)

$0.69(10.67 * * *)$

$0.83(16.83 * * *)$

$0.79(14.61 * * *)$

Job Dissatisfaction -> Intention to leave (H5b)

$0.52(6.94 * * *)$

*** Significant at 0.01 (2-tailed test)

\section{CONCLUSION}

\section{Discussion and Implication}

The purpose of this study is to investigate the salary peak system and its impact on employee behavior. Based on the proposed model, attitudes towards salary peak system and its impacts on motivation, job satisfaction, and loyalty or intention to leave after being applied to salary peak system are measured. Through this analysis, the effects of monetary and non-monetary factors on attitudes toward the salary peak system are proven. Three major monetary factors such as salary, incentive and pension affect workers' attitudes toward the salary peak system. Changes in monetary factors, especially salary reduction, negatively affect attitudes toward the salary peak system. Also, nonmonetary factors such as word of mouth, job position or employment status, perceived job importance and organizational commitment are proven to be important factors affecting attitudes toward the salary peak system. Respondents tend to have negative attitudes toward changes in non-monetary factors under the salary peak system. This study found that the effects of monetary factors showed slightly higher importance than the effects of nonmonetary factors. This means that monetary factors are more significant determining factors of attitudes toward the salary peak system. Further, this study also found that negative perception and attitudes towards salary peak system also tend to negatively affect motivation, satisfaction, loyalty, and increase intention to leave. In addition, the results show decreased motivation, satisfaction and loyalty to work and company and increased worker's intention to quit under the system.

This study has managerial implications. The introduction of salary peak system became an important issue for human resources management as companies, considered their older workers and retirement in an aging society. Many companies introduced the salary peak system or are planning to start this system according to spontaneous intention. Whatever induces businesses to consider the salary peak system, it is not just cost management related to employee retirement, but human resources management considering employee psychological factors. In addition to cost management by reducing salary or incentives, companies should consider how to manage employee's motivation, satisfaction, and loyalty that can be affected by the salary peak system. According to Naseem, Sheikh and Malik (2011), employee satisfaction determines the organizational success. How companies manage employee behavior is the crucial key of successful salary peak system. In this regards, this study contributes the measurement of the relationship between the salary peak system and employee attitudes. This study closely looked into streams of salary peak system to behaviors after being applied to this system. Further, an increasing number of companies are adopting a retirement extension systems which adjust wages instead of extending retirement age (http://www.kefplaza.com). Therefore, lowered wages without guaranteed extension will also affect reduced motivation and job satisfaction.

The results of this study provide theoretical implications. While most applications of motivation, satisfaction and loyalty theories and models have been investigated in customer behavior studies, this study expands the concept to employee motivation, satisfaction and loyalty or intention to leave by exploring employee attitudes. This study investigated the effects of monetary factors and non-monetary factors on attitudes toward the salary peak system. This study also examined how negative attitudes toward the salary peak system affect worker motivation, satisfaction, and loyalty. The results of the tested hypotheses implied that worker's negative attitudes toward the salary peak system have negative impacts on their psychological factors.

In terms of public policy implications, the salary peak system has been developed in order to effectively manage older workers in a rapidly aging society (http://news.mk.co.kr/). In addition to the proposed retirement plan by the government, the salary peak system was considered as a solution to support people who are near retirement age. 
However, the salary peak system should be improved by considering legal and financial issues to maximize employee satisfaction and loyalty. Motivation, dissatisfaction, disloyalty and increased intention to leave should be importantly considered for public policy decision-making regarding the retirement system. Previous studies (Choi, 2013; Kim, 2012; An, 2011) also examined that the salary peak system might cause conflicts and might not effective solution for youth unemployment. Therefore, more effective policies for salary system and social problems of unemployment should be needed.

\section{Limitation of Study and Future Research}

This study has some limitations. First of all, the sample size is not large enough to generalize the results for all workers' behavior. Moreover, this study did not compare behaviors by classifications such as gender, academic background, job ranks or working years. Future study should consider different effects based on demographic. Future study might consider effects based on different sectors such as private and public sectors. Future studies should be applied to compare similar retirement programs by applying cases of various countries. Further study could involve qualitative research by applying in-depth interviews to investigate internal perceptions of employees. The causal relations of the variables could be explored for further research. Further study should also consider the causal relations of salary peak system and youth employment.

\section{AUTHOR BIOGRAPHY}

Yoon C. Cho is professor at the KDI School of Public Policy and Management. She has publications in the Journal of Business Research, Advanced in Consumer Research, and Journal of Business Economics Research, etc.

Yeji Kim is a Graduate of KDI School of Public Policy and Management.

\section{REFERENCES}

Abdullah, Alkhaliel Adeeb (2013), "Relationship of Non-Monetary Incentives, Job Satisfaction and Employee Job Performance," International Review of Management and Business Research, 2(4), 1085-1091.

Adams, J. S. (1963), “Towards an Understanding of Inequality,” Journal of Abnormal and Normal Social Psychology, 67, 422436.

Ajzen, Icek and Fishbein, Martin (1980), Understanding Attitudes and Predicting Social Behavior. New Jersey: Prentice-Hall. An, Jooyeop (2011), Research on Possibility of Employment Replacement cross the Age, Korea labor Research Institute.

An, Seung Chan (2003), "Concerns of Misuse for Wage Reduction under Salary Peak System,” Edaily, Retrieved August 15, 2014 from http://www.edaily.co.kr/news/NewsRead.edy?DCD=A601\&newsid=01177526570076488

Arshad Muhammad Adeel, Masood Muhammad Tahir and Amin Ghazala (2013), "Effects of Performance Appraisal Politics on Job Satisfaction, Turnover Intention and Loyalty to Supervisor: Study with Reference to the Telecom Organizations of Pakistan," International Review of Management and Business Research, 2(3), 653-673.

Azar, Maryam and Shafighi, Ali Akbar (2013), "The Effect of Work Motivation on Employees' Job Performance: Case Study: Employees of Isfahan Islamic Revolution Housing Foundation," International Journal of Academic Research in Business and Social Sciences, 3(9), 432-445.

Barker, T. David and Clark, L. Robert (1980), "Mandatory Retirement and Labor-Force Participation of Respondents in the Retirement History Study," Social Security Bulletin, 43(11), 1-11.

Bari, Neelam, Arif, Uzma and Shoaib, Almas (2013), "Impact of Non-Financial Rewards on Employee Attitude \& Performance in the workplace: A Case Study of Business Institute of Karachi," International Journal of Scientific \& Engineering Research, 4(7), 2554-2559.

Basak, Ecem, Ekmekci, Esin, Bayram, Yagmur and Bas, Yasemin (2013), "Analysis of Factors That Affect the Intention to Leave of White-collar Employees in Turkey Using Structural Equation Modelling," World Congress on Engineering and Computer Science, II, October, San Francisco, USA, 23-25.

Becker, Mary Jane, Trail, Thomas F., Lamberts, Martha B. and Jimmerson, Ronald M. (1983), "Is Preretirement Planning Important?" Journal of Extension, May-June.

Bem, Daryl J. (1967), "Self-Perception: An Alternative Interpretation of Cognitive Dissonance Phenomena”, Psychological Review, 74(3), 183-200.

Buttle, Francis, A. (1998), "Word of Mouth: Understanding and Managing Referral Marketing," Journal of Strategic Marketing, 6(3), 241-254.

Byun, Sang Woo and Kim, Hak-don (2005), “A Study on the Root Plan of Wage Peak System,” Korean Academy of Human Resource Management, 12(1), 47 60. 
Card, David, Alexandre, Mas, Moretti, Enrico and Saez, Emmanuel (2011), "Inequality at Work: The Effect of Peer Salaries on Job Satisfaction," American Economic Review, 102(6), 2981-3003.

Chartrand.T. L., and Bargh, J. A. (1999), “The Chameleon Effect: The Perception-Behavior Link and Social Interaction,” Journal of Personality and Social Psychology, 76(6), 893-910.

Charity A., Ezigbo and Timinepere, Court Ogele (2011), "The Effects of Monetary and Non-Monetary Rewards on the Employees' Performance in Manufacturing Firms in Rivers State, Nigeria," Journal of Sociology, Psychology and Anthropology in Practice, 3(1), 120-129.

Choi, Seung Kun (2013), "Introduction of Salary Peak system: A Matter of labor management Conflict," Newstomato, Retrieved from August 15, 2014 from http://www.newstomato.com/readNews.aspx?no=358476

Choi, Sang Long, Musibau, Akintunde Ajagbe, Khalil, Md Nor and Ebi, Shahrin Suleiman (2012), "The Approaches to Increase Employees' Loyalty: A Review on Employees’ Turnover Models," Australian Journal of Basic \& Applied Sciences, 6(10), 282-291.

Clark, Andrew E. and Oswald, Andrew J. (1996), "Satisfaction and Comparison income," Journal of Public Economics, 61(3), 359-381.

Davy, J. A., Kinicki, A. J. and Scheck, C. L. (1997), “A test of Job Security’s Direct and Mediated Effects on Withdrawal Cognitions," Journal of Organizational Behavior, 18(4), 323-349.

Eichhorst, Werner, Gerard, Maarten, Kendzia, J. Michael, Mayrhuber, Christine, Nielsen, Connie, Rünstler, Gerhard, Url, Thomas, "Pension Systems in the EU - Contingent Liabilities and Assets in the Public and Private Sector," I Z A Research Report, 42, 1-144.

Ebbinghaus, Bernhard (2000), "When Labour and Capital Collude: The Varieties of Welfare Capitalism and Early Retirement in Europe, Japan and the USA," working paper, Max Planck Institute for the Study of Societies, Cologne, Germany/Center for European Studies, Harvard University, Cambridge, Mass.

Ahmed Elsayed, Andries de Grip, Didier Fouarge, Raymond Montizaan (2014), "Gradual Retirement and Labour Supply of Older Workers: Evidence from a Stated Preference Analysis," parthen-impact.com.

Geneviève, Reday-Mulvey and Lei Delsen (1996). Gradual Retirement in the OECD Countries, a Summary of the Main Results, The Geneva Papers on Risk and Insurance, 21, 502-523.

Han, Hyuk (2013), "Sustainability and effect verification of wage peak system as an alternative to an aging society," working paper, Seoul National University.

Herzberg, F. (1966), Work and the nature of man, Cleveland: World Publishing Company.

Hussain, Nehal and Khalid, Kanwal (2011), "Impact Of Karasek Job Demand Control Model on the Job Satisfaction of the Employees of Nadra," Interdisciplinary Journal of Contemporary Research in Business, 3(5), 564-594.

Hwang, Soo Kyeong (2006), Wage Structure and Skill Development in Korea and Japan, Japan Institute for Labour Policy and Training (JILPT), Retrieved September 12, 2014 from http://www.jil.go.jp/profile/documents/Hwang.pdf

Karimi, Rabia, Malik, Muhamad Imran and Hussain, Saddam (2011), "Examining the Relationship of Performance Appraisal System and Employee," International Journal of Business and Social Science, 2(22), 243-247.

Kim, Dong Bae (2014), "Introduction of Salary Peak system Only 8.3\%...Rising issue after law, retirement age extension,” Nara of Korea Development Institute, 7, 30.

Kim, Myung-Sik (2012), “The Case Studies of Company Operations by the Type of Wage peak system,” working paper, Graduate School of Seoul Christian University.

Lazear, Edward P. (1979), "Why is There Mandatory Retirement?” The Journal of Political Economy, 87(6), 1261-1284.

Lee, Hee Soung (2006), "A study on the Law-Policy and Introduction Background of the Wages Peak System," The Korean Association of Law and Policies, 6(2), 603 623.

Lee, Ji man and Kim Sang Jun (2006), "A Study of home and domestic cases of salary peak system and effectiveness," Kefplaza, Retrieved July 20, 2014 from http://www.kefplaza.com/index.jsp, 1-45.

Lee, Ji Man, Park, Sung Hoon, Chung, Seung Wha, Kang, Chul Hee, and Cho, Sang Mi (2012), “The Peak Wage System in Korea in Comparison to Japanese Experiences", Journal of Korean Academy of Human Resource Management, 19(1), $1 \sim 26$.

Lee, Jong Soo (2009), (The) dictionary of public administration terms, Seoul: Dae Young Co.

Locke, E. A., \& Latham, G. P. (1990), A theory of goal setting and task performance. Upper Saddle River, NJ: Prentice Hall.

Markus, H. and Kitayama, S. (1991), "Culture and Self: Implications for Cognition, Emotion and Motivation," Psychological Review, 98(2), 224-253.

Maslow, A (1954), Motivation and personality, New York, NY: Harper.

Merrill Lynch: Bank of America Corporation (2014), "Work in Retirement: Myths and Motivations: Career Reinventions and the New Retirement Workscape," 1-20.

Nandanwar, M. V., Surnis, S. V., and Nandanwar, L. M. (2010), "Incentives as a Tool towards Organizational Success of Entrepreneur Business: A Case Study of Small Scale Pharmaceutical Manufacturing Unit," International Journal of Economics and Business Modeling, 1(2), 15-20.

Mehta, Ahmed Muneeb (2014), "Impact of Monetary Rewards on Employee Performance and Job Satisfaction: An Empirical Study of the Insurance Sector of Pakistan," Interdisciplinary Journey of Contemporary Research in Business, 5(11), 276-283. 
Naegele, Laura, Dhéret, Claire, and Thode, Eric (2013), "Second Career Labor Markets for Older Workers: Framing the Debate on More Employment opportunities for Older Workers,” working paper, European Policy Center: BertelsmannStiftung, $1-12$.

Neyshabor, Ali Jamali and Rashidi, Parvin (2013), “An Investigation of the Relationship between Job Enrichment and Organizational Commitment," International Journal of Research in Organizational Behavior and Human Resource Management, 1(3), 57-65.

Parker, S. K. (1998), "Enhancing Role Breadth Self-Efficacy: The Roles of Job Enrichment and Other Organizational Interventions," Journal of Applied Psychology, 83(6), 835-852.

Pandey, Chetna and Khare Rajni (2012), "Impact of Job Satisfaction and Organizational Commitment on Employee Loyalty," International Journal of Social Science\& Interdisciplinary Research, 1(8), 26-41.

Richard Savvedra and Seog, K. Kwun (2000), “Affective states in job characteristics theory”, Journal of Organizational Behavior, Special Issue, 21(2), 131-146.

Rousseau, D. (1995), Psychological contracts in organizations: Understanding written and unwritten agreements, Thousand Oaks, CA: Sage Publications.

Rynes, Sara L., Gerhart, Barry and Mintte, Kathleen A. (2004), "The Importance of Pay in Employee Motivation: Discrepancies between What People Say and What They do," Human Resource Management, 43(4), 381-394.

Scott, Carol A. (1978), "Self-Perception Processes in Consumer Behavior: Interpreting One's Own Experiences," Advances in Consumer Research, 5,714 720.

Sudin, Suhaimi (2011), "Fairness of and Satisfaction with Performance Appraisal Process," Journal of Global Management, 2(1), 66-83.

Suma, Saimir and Lesha, Jonida (2013), "Job Satisfaction and Organizational Commitment: The Case of Shkodra Municipality," European Scientific Journal, 9(17), 41-51.

Tae, Won Yu, Ryu, Ji Sung, Son, Min Jung, Cho, Hyun Kook, Kim, Tae Jung, Kim, Sun Bin, Lee, Un Ho and Lee, Jong Hoon (2009), "Unemployment's detonator: solutions for middle-aged employment instability," Samsung Economic Research Institute, 1-33.

Utman, Christopher H. (1997), "Performance Effects of Motivational State: A Meta-Analysis," Personality and Social Psychology Review, 1(2), 170-182.

Van Dalen, Hendrik P. and Henkens, Kène (2014), "Why Demotion of Older Worker is a No-Go Area A Vignette Study among Managers," working paper, Netherlands Interdisciplinary Demographic Institute, University of Groningen, Tilburg University and University of Amsterdam.

Van Eerde, Wendelien and Thierry, Henk (1996), "Vroom's Expectancy Models and Work-Related Criteria: A Meta-Analysis," Journal of Applied Psychology, 81(5), 575-586.

Vroom, V. H. (1964), Work and motivation. San Francisco, CA: Jossey-Bass.

Wachter, von Till Marco (2002), "The End of Mandatory Retirement in the US: Effects on Retirement and Implicit Contracts," Center for Labor Economics Working Paper, 49, University of California Berkeley, 1-60.

Wan, Hooi Lai (2012), "Employee Loyalty at the Workplace: The Impact of Japanese Style of Human Resource Management," International Journal of Applied HRM, 3(1), 1-17.

Waskiewicz, Stanely Peter (1999), "Variables that Contribute to Job Satisfaction of Secondary School Assistant Pricipals," working paper, Faculty of the Virginia Polytechnic Institute and State University.

Yasar, Mehmet Fatih, Emhan, Abdurrahim and Ebere, Pauline (2014), "Analysis of Organizational Justice, Supervisor Support, and Organizational Commitment: A Case Study of Energy Sector in Nigeria," Journal of Business Studies Quarterly, $5(3), 37-46$.

Yoo, Dong Hae and Ha, Dong Suk (2010), (The) dictionary of public administration terms, Seoul: New Information Media.

Zedelius, M. Claire, Veling, Harm, Bijleveld, Erik and Aarts, Henk (2012), "Promising High Monetary Rewards for Future Task Performance Increase Intermediate Task Performance,” Plosone, 7(8), 1-9.

\section{ONLINE RESOURCES}

Age UK (2013), “Working over 50: Your Options for staying in work”, Retrieved July 12, 2014 from http://www.ageuk.org.uk/Documents/EN-GB/Information guides/AgeUKIG34_Working_Past_Retirement_inf.pdf.pdf?dtrk=true

AARP (2006), "Phased Retirement and Flexible Retirement Arrangements: Strategies for Retaining Skilled Workers", Retrieved July 6, 2014 from http://assets.aarp.org/www.aarp.org_/articles/money/employers/phased_retirement.pdf, http://www.esdc.go.kr/bbs/viewbody.asp?code=news\&id=319\&number=319

Ministry of Employment and Labor (2014), Retrieved June 25, 2014 from http://www.moel.go.kr/policyinfo/aged/view.jsp?cate $=1 \&$ sec $=1$

Ministry of Strategy and Finance (2010), Retrieved June 25, 2014 from http://www.mosf.go.kr/news/news05a.jsp?actionType=view\&runno=6467

The Employment Development Department of State of California (2014), Retrieved June 25, 2014 from http://www.edd.ca.gov/Unemployment/Work_Sharing_Claims.htm 
OECD (2011), Pensions at a Glance 2011: Retirement-Income Systems in OECD and G20 Countries, http://www.oecd.org/els/public-pensions/pensionsataglance2011.htm

TIAA (2012), "Early or Phased Retirement Incentive Programs for Higher Education", https://www.tiaacref.org/public/pdf/Early\%20or\%20Phased\%20Retirement\%20Incentive\%20Programs.pdf, http://news.mk.co.kr/, http://www.kefplaza.com/kef/labor_infocus_view.jsp?num=842 


\section{NOTES}

